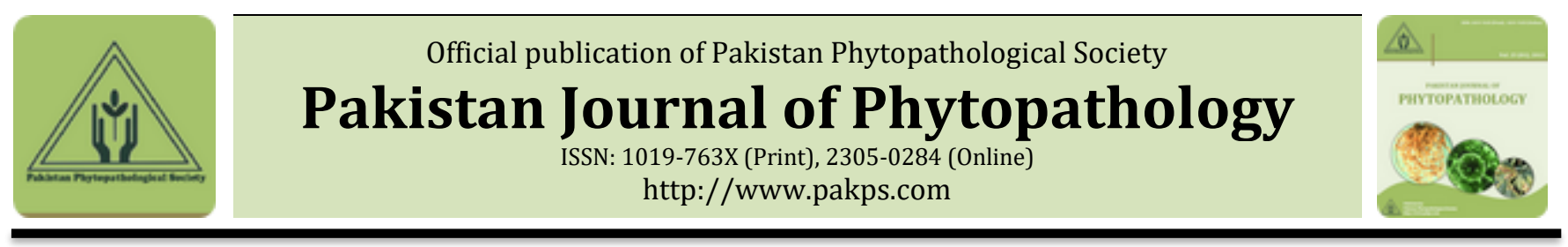

\title{
EVALUATION OF NEEM PRODUCTS AGAINST DAMPING OFF DISEASE OF TOMATO
}

\author{
aAli H. Mangi, aAbsar M. Jiskani*, bMuhammad I. Khaskheli, aMuhammad M. Jiskani, 'Gul B. Poussio, \\ a'Rawal A. Qambrani, aMansoor A. Mahar, dAbrar M. Jiskani \\ ${ }^{a}$ Department of Plant Pathology, Sindh Agriculture University, Tandojam, Pakistan. \\ ${ }^{b}$ Department of Plant Protection, Sindh Agriculture University, Tandojam, Pakistan. \\ ${ }^{c}$ Agriculture Research Institute, Tandojam, Pakistan. \\ d Department of Horticulture, Sindh Agriculture University, Tandojam, Pakistan.
}

\begin{abstract}
A B S T R A C T
Tomato damping off is one of the most serious and widespread disease in Pakistan and the world, due to the harmful effects of synthetic chemicals to humans, environment and animals, this study aims to manage them. The use of plant extracts has been recognized as one of the most encouraging and safe options for eco-friendly disease management. Therefore, this study was conducted to check the efficacy of different neem products e.g. Neem seed, Neem seed coat, Neem seed without coat. Dry neem leaves, Saw dust and Bio-neem compost on the tomato seeds, by dipping for 3 and 5 minutes and then sown in steam-sterilized soil artificially infested with Fusarium oxysporum f.sp. lycopersici. The maximum seed germination, root length $(\mathrm{cm})$, shoot length $(\mathrm{cm})$, root weight $(\mathrm{g})$ and shoot weight $(\mathrm{g})$ were recorded when the seeds were dipped for 5 minutes in neem seed decoction, followed by bio-neem compost and neem seed decoction for 3 and 5 minutes respectively. Seed germination and whole plant growth were reduced when untreated seeds were sown in artificially infested soil followed by seeds dipped in dried neem leaves decoction for 3 minutes and neem seed decoction (without coat) for 3 minutes. The seedling mortality was decreased as a time of posture of dipping of seeds was increased, and that was devoted to uninoculated soil. The seedling was increased as the age of tomato plants increased. The mortality was decreased after 30 days of sowing followed by 45 days of sowing, and when the seeds were treated with a decoction prepared from neem sawdust and neem seed decoctions as well as bioneem compost, respectively. Interestingly, neem products are considered as a potential plant for controlling tomato damping off for the first time in the current study. According to the results, it can be used as a potential plant source for eco-friendly control of tomato damping off.
\end{abstract}

Keywords: Botanical control, Disease management, Fusarium oxysporum, lycopersici, Neem extract.

\section{INTRODUCTION}

Tomato, Lycopersicon esculentum (Mill.) are rich in vitamin $\mathrm{C}$, mineral salts and are recommended for patients with constipation, diabetes, heart, and body diseases (Alajrami and Abu-Naser, 2020). Tomato is the second largest vegetable produced in Pakistan (Sajjad et al., 2011). It is also an economically important crop of Hyderabad, Badin, Thatta, Mirpurkhas, Nawabshah, Karachi, Naushahro Feroze, Larkana and Sukkur districts

Submitted: November 27, 2020

Revised: June 15, 2021

Accepted for Publication: June 19, 2021

* Corresponding Author:

Email: amjiskani@hotmail.com

(C) 2021 Pak. J. Phytopathol. All rights reserved. of Sindh (Pakistan). It is a relatively long season vegetable crop of the tropical world and is a major source of income (Khokhar, 2013).

It is one of the most susceptible vegetable crops causing 70 to $95 \%$ yield losses due to diseases in tropical regions (Lukyanenko, 1991). The world over reported diseases of tomato are about 59, including 17 viral, 28 fungal, 4 bacterial, 3 plant-parasitic nematode, and 4 miscellaneous diseases or disorders (Jones et al., 2015). Among these diseases, dampingoff of seedlings and wilt of the adult crop (Fusarium oxysporum f. sp. lycopersici, Rhizoctonia solani, Pythium spp. and Verticillium albo-atrum), fruit rot (Alternaria tenuis) are the most common and destructive disease of tomato (Figure 1) 
(Gunasekaran et al., 1994; Jiskani et al., 2021; Lucas and Campbell, 2012).

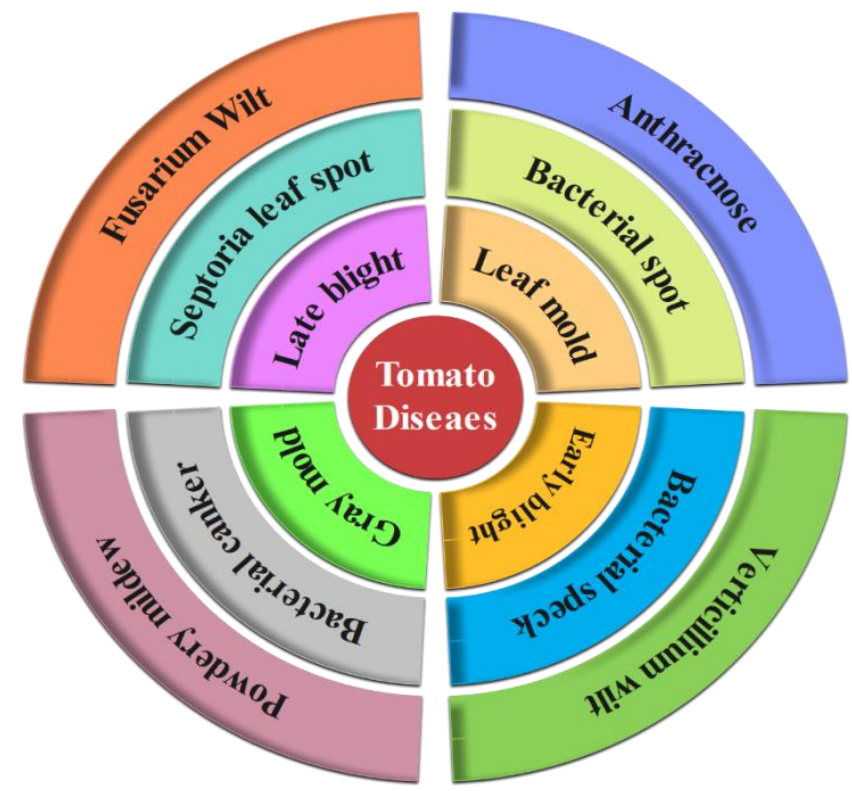

Figure 1. Most common diseases of tomato

Seed treatment provides an excellent anti-damping-off effect in the process of plant growth and development and can promote plant growth for a long time (Salman and Abuamsha, 2012). The use of fungicides as seed treatment remained dominant throughout the world, with a $68 \%$ share, followed by insecticides at $11 \%$ in the market (Schwinn, 1994). Several synthetic fungicides have been used in the control of commercially important crop diseases. However, their continued use in the agricultural system has brought some side effects to the agricultural ecosystem and the health of consumers (Pandey et al., 2016). Seed dressing fungicides are quite dangerous for both human as well as animal health, and even their judicious uses make the environment polluted.

The literature available on the disease indicated that very little work had been reported on tomato dampingoff disease in Sindh (Pakistan), hence keeping in view the losses caused by the disease and various health hazards due to non-judicious use of pesticides, the present research work was conducted to assess the effect of different neem products against damping-off of tomato seedlings caused by Fusarium oxysporum f. sp. lycopersici.

\section{MATERIALS AND METHODS}

Studies on the effect of different neem products (Figure 2) against Fusarium oxysporum f. sp. lycopersici causing tomato damping-off, seedlings were carried out in the Department of Plant Pathology, Sindh Agriculture University, Tandojam (Pakistan).

Collection of diseased samples and isolation of fungus: Tomato plants with damping-off disease symptoms were collected from different fields surrounding Tandojam. The diseased specimens were taken in plastic bags and carried to the laboratory of Department of Plant Pathology, Sindh Agriculture University, Tandojam for isolation of fungus.

The isolation was done through standard methods by cutting small pieces from the infected samples and treating with $0.01 \% \mathrm{HgCl}^{2}$ solution for 1 minute each. The surface-sterilized five tissues were kept in Petri dishes containing sterilized potato-dextrose-agar (PDA) medium. All the plates were incubated at room temperature $\left(30 \pm 10^{\circ} \mathrm{C}\right)$ for $7-10$ days. The dominantly isolated fungi were sub-cultured and multiplied from time to time throughout the entire research experiment.

Identification of the causal fungus: The predominantly isolated disease-causing fungus was purified and identified by studying typical colony characteristics, mycelial growth, and the presence of conidia, with the help of microscope observations using standard diagnostic keys.

Effect of different neem products on seed germination, plant growth, and damping-off disease: Before sowing, tomato seeds were dipped in various neem products (Figure 2) to observe their effects on tomato seed germination, plant growth, and tomato damping-off.

Preparation of stock solution: The 5\% solution of each neem product except bio-neem compost was prepared by thoroughly washing and grinding. $50 \mathrm{~g}$ of each were macerated individually in the blender with $250 \mathrm{ml}$ of distilled water, and then $1.0 \mathrm{~g}$ of washing powder was added. The extracted solution was kept for 16 hours and, after that, added more $50 \mathrm{ml}$ distilled water to each neem extract product to get $5 \%$ concentration.

Seed treatment: Seed treatment was made separately with various neem products (Figure 2) at different dipping timings (3 and 5 minutes). 50 seeds/pot, treated and untreated, were seeded in pots containing $2 \mathrm{~kg}$ of steamsterilized soil infested with a fresh culture of Fusarium oxysporum f. sp. lycopersici. The untreated seeds on infested and un-infested soil were served as control. 


\section{Neem products used for seed treatment}

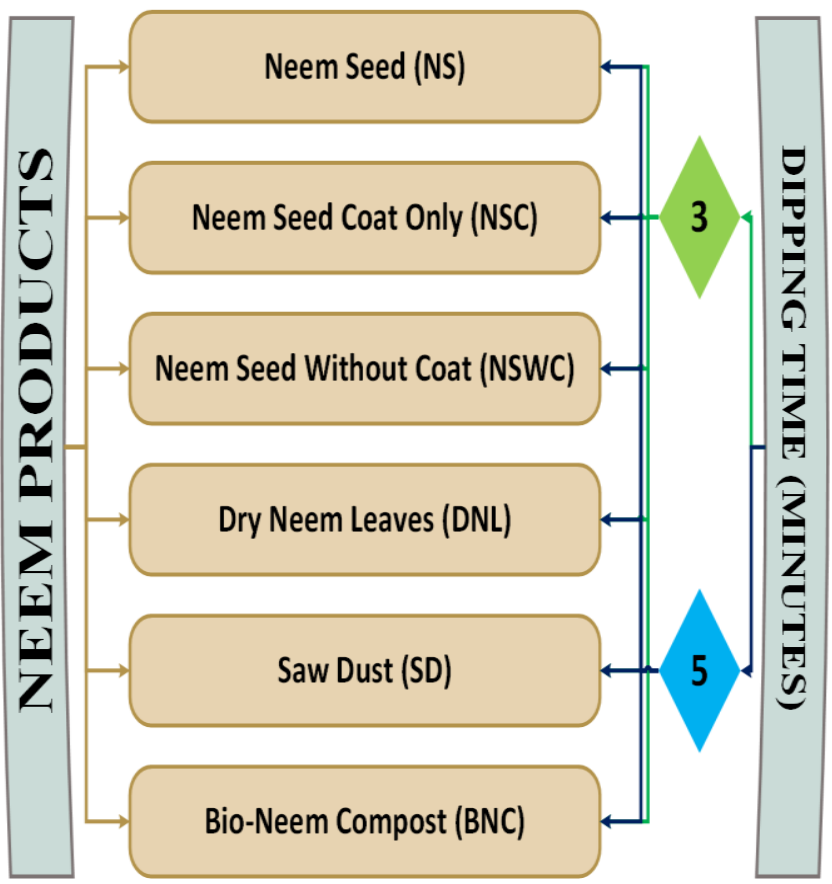

Figure 2. Various neem products used for seed treatment

* Obtained from LRSDA, Ratanabad, Mirpurkhas.

Observations: The observations were recorded on germination percent after 08 and 10 days of sowing. The mortality percentage was calculated by calculating the number of dead plants 30 days and 45 days after sowing. The data of shoot and root length (cm), weight (g), and development of the disease were recorded.

Randomized complete block design (RCBD) was used in the experiment with 4 replicates. The data were statistically analyzed with the computer software "Student Edition of Statistix" P $<0.05$, and the analysis of variance was performed.

\section{RESULTS AND DISCUSSION}

Symptoms of the disease: The damping-off disease affected the seed, seedling, and roots of the tomato plants. Seeds grown on infested soil fail to germinate. Young seedlings became died (pre-emergence damping-off). Seedlings that have previously appeared also damaged at roots and stems nearly at or below the soil line. The infected plants also showed yellowing of leaves become stunted and gradually cover large root areas. The entire root gets rotted and finally dried up. Similar symptoms are reported by Zulfikar et al. (2018), who stated that post-emergence damping-off attacks seedlings as they emerge above ground, pinching off the stem tissue at or just below the soil line. Black et al. (1991) reported that Rhizoctonia solani, Pythium spp. and Fusarium spp. are worldwide distributed, causing damping-off and root rot in tomato. Plants become stunted due to root rots or stem collar rot. Under severe conditions, the stems become girdled, followed by drooping and dying of plants. The diseases can occur either before or after emergence of seedlings.

Identification of the causal fungus: The infected root pieces showed brownish discoloration of the fungus. The fungus produced white cottony mycelial growth with a large quantity of single-celled microconidia and curved macro-conidia. Therefore, the fungus was identified as Fusarium oxysporum f. sp. lycopersici (Sacc.). Wong (2003) by studying colony characteristics as described by (Barnett and Hunter, 1972; Ellis, 1971) morphology of micro and macroconidia as reported by Gunasekaran et al. (1994); Kuprashvili (1996) and Lucas and Campbell (2012) also reported that damping-off of tomato seedlings and wilt of adult crop caused by Fusarium oxysporum f. sp. lycopersici. El-Shami et al. (1993) and Gunasekaran et al. (1994) also observed the association of Fusarium oxysporum f. sp. lycopersici from tomato seedlings causing a high level of damping-off disease.

Effect of different neem products on seed germination: The germination percent and germinated seeds of tomato plant was significantly increased with the usage of neem products as compare to control. The number of germinated seeds/pot was noted higher in NS after 8 and 10 days (35.67 and 41.67) with germination percent of 71.33 and $83.33 \%$ (Table 1) respectively, when seeds were dipped in neem seed decoction for 5 minutes. It was followed by BNC (33.00 and 39.00) with seed germination percent of 66.00 and $78.00 \%$, as compared to seeds dipped in neem seed decoction for 3 minutes (32.67 and 37.00) with germination percent of 65.33 and $74.00 \%$. The germinated seeds/pot and germination percent was lower in untreated and inoculated seeds (19.33 and 25.67 seeds/pot with 38.67 and $51.33 \%$ ) followed by Untreated uninoculated seeds (28.33 and 31.67 seeds/pot with 56.67 and 63.33 germination percent) on 8 and 10 days after sowing. 
Table 1. Effect of neem products on seed germination of tomato seedlings

\begin{tabular}{|c|c|c|c|c|c|}
\hline \multirow{2}{*}{ Neem products } & \multirow{2}{*}{ Dipping time (Minutes) } & \multicolumn{2}{|c|}{ Germinated seeds } & \multicolumn{2}{|c|}{ Germination \% } \\
\hline & & 8 Days & 10 Days & 8 Days & 10 Days \\
\hline \multirow{2}{*}{ NS } & 3 & 32.67 & 37.00 & 65.33 & 74.00 \\
\hline & 5 & 35.67 & 41.67 & 71.33 & 83.33 \\
\hline \multirow{2}{*}{ NSC } & 3 & 22.00 & 28.00 & 44.00 & 56.00 \\
\hline & 5 & 29.33 & 34.00 & 58.67 & 68.00 \\
\hline \multirow{2}{*}{ NSWC } & 3 & 21.33 & 26.67 & 42.67 & 53.33 \\
\hline & 5 & 24.67 & 30.33 & 49.33 & 60.67 \\
\hline \multirow{2}{*}{ DNL } & 3 & 21.00 & 26.00 & 42.00 & 52.00 \\
\hline & 5 & 23.00 & 29.67 & 46.00 & 59.33 \\
\hline \multirow{2}{*}{ SD } & 3 & 28.67 & 32.67 & 57.33 & 65.33 \\
\hline & 5 & 31.67 & 36.33 & 63.33 & 72.67 \\
\hline \multirow{2}{*}{$\mathrm{BNC}$} & 3 & 30.00 & 35.67 & 60.00 & 71.33 \\
\hline & 5 & 33.00 & 39.00 & 66.00 & 78.00 \\
\hline Untreated inoculated & - & 19.33 & 25.67 & 38.67 & 51.33 \\
\hline Untreated uninoculated & - & 28.33 & 31.67 & 56.67 & 63.33 \\
\hline $\mathrm{P}<0.05$ & - & 3.92 & 4.79 & - & - \\
\hline \multicolumn{6}{|c|}{ 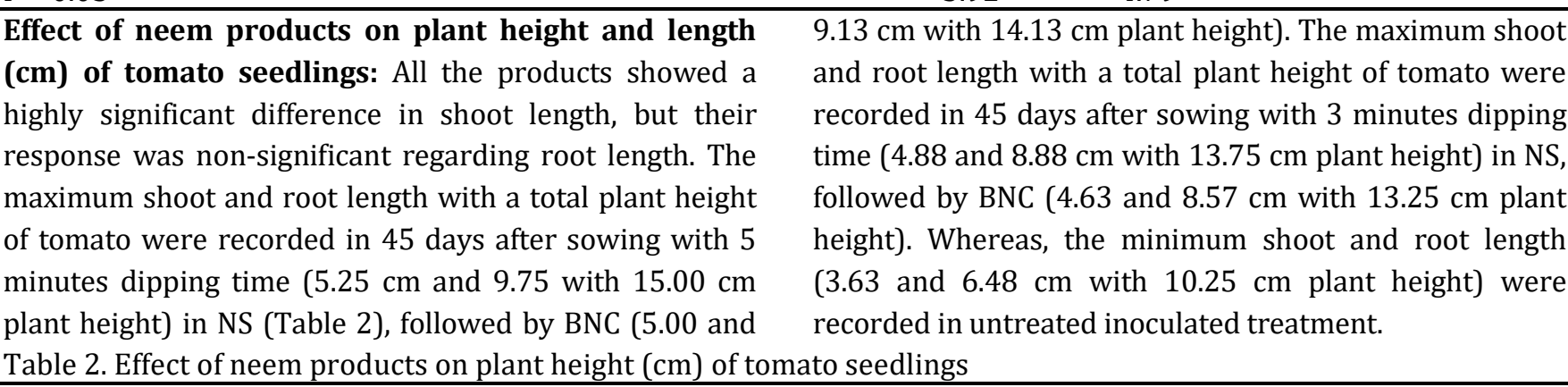 } \\
\hline \multirow{2}{*}{ Neem produc } & \multirow{2}{*}{$\begin{array}{c}\text { Dipping time } \\
\text { (Minutes) }\end{array}$} & & Length $(\mathrm{cm})$ & \multirow{2}{*}{\multicolumn{2}{|c|}{ Height $(\mathrm{cm})$}} \\
\hline & & Root & Shoot & & \\
\hline \multirow{2}{*}{ NS } & 3 & 4.88 & 8.88 & \multicolumn{2}{|c|}{13.75} \\
\hline & 5 & 5.25 & 9.75 & \multicolumn{2}{|c|}{15.00} \\
\hline \multirow{2}{*}{ NSC } & 3 & 3.75 & 7.25 & \multicolumn{2}{|c|}{11.00} \\
\hline & 5 & 4.38 & 8.50 & \multicolumn{2}{|c|}{12.88} \\
\hline \multirow{2}{*}{ NSWC } & 3 & 3.75 & 7.13 & \multicolumn{2}{|c|}{10.88} \\
\hline & 5 & 4.00 & 7.63 & & 63 \\
\hline DNI & 3 & 3.63 & 7.13 & & 75 \\
\hline DNL & 5 & 3.75 & 7.50 & & 25 \\
\hline cD & 3 & 4.25 & 7.88 & & 13 \\
\hline SD & 5 & 4.75 & 8.75 & & 50 \\
\hline DNC & 3 & 4.63 & 8.57 & & 25 \\
\hline BINC & 5 & 5.00 & 9.13 & & 13 \\
\hline Untreated inoculated & - & 3.66 & 6.48 & & 25 \\
\hline Untreated uninoculated & - & 4.25 & 8.25 & & 50 \\
\hline $\mathrm{P}<0.05$ & - & N.S & 1.14 & & 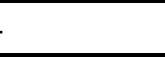 \\
\hline
\end{tabular}

N. S= Non-Significant 
Effect of different neem products on tomato plant weight: The root and shoot weight were also increased ( 0.12 and $0.22 \mathrm{~g}$ ) in seeds when dipped for 5 minutes in NS with $0.34 \mathrm{~g}$ total plant height (Table 3), followed by BNC for 5 minutes $(0.11$ and $0.21 \mathrm{~g}$ with $0.31 \mathrm{~g}$ total plant weight, NS for 3 minutes $(0.10$ and $0.20 \mathrm{~g}$ with total $0.30 \mathrm{~g}$ plant weight) as compared to a SD for 5 minutes ( 0.10 and $0.20 \mathrm{~g}$ ) with $0.30 \mathrm{~g}$ plant weight, BNC for 3 minutes ( 0.10 and $0.19 \mathrm{~g}$, with $0.29 \mathrm{~g}$ plant weight), and un-treated and un-inoculated seeds $(0.010 \mathrm{~g}$ and $0.19 \mathrm{~g}$ with plant height $(0.28 \mathrm{~g})$ after 45 days of sowing. Table 3. Effect of neem products on plant weight of tomato seedlings

\begin{tabular}{|c|c|c|c|c|}
\hline \multirow{2}{*}{ Neem products } & \multirow{2}{*}{ Dipping time (Minutes) } & \multicolumn{3}{|c|}{ Weight (g) } \\
\hline & & Root & Shoot & Total Plant weight \\
\hline \multirow{2}{*}{ NS } & 3 & 0.10 & 0.20 & 0.30 \\
\hline & 5 & 0.12 & 0.22 & 0.34 \\
\hline \multirow{2}{*}{ NSC } & 3 & 0.08 & 0.18 & 0.26 \\
\hline & 5 & 0.10 & 0.19 & 0.29 \\
\hline \multirow{2}{*}{ NSWC } & 3 & 0.07 & 0.18 & 0.25 \\
\hline & 5 & 0.09 & 0.19 & 0.28 \\
\hline \multirow{2}{*}{ DNL } & 3 & 0.07 & 0.14 & 0.22 \\
\hline & 5 & 0.09 & 0.18 & 0.26 \\
\hline \multirow{2}{*}{ SD } & 3 & 0.09 & 0.19 & 0.28 \\
\hline & 5 & 0.10 & 0.20 & 0.30 \\
\hline \multirow{2}{*}{$\mathrm{BNC}$} & 3 & 0.10 & 0.19 & 0.29 \\
\hline & 5 & 0.11 & 0.21 & 0.31 \\
\hline Untreated inoculated & - & 0.07 & 0.13 & 0.20 \\
\hline Untreated uninoculated & - & 0.10 & 0.19 & 0.28 \\
\hline $\mathrm{P}<0.05$ & - & N.S & N.S & - \\
\hline
\end{tabular}

N. S= Non-Significant

Effect of different neem products on mortality of tomato seedling: The mortality of tomato seedlings due to damping-off disease caused by $F$. oxysporum f. sp. lycopersici were varies from one to another product. The mortality was decreased as the period for dipping of seeds was increased; there was no mortality when untreated seeds were sown in uninoculated (uninfested) soil, but the mortality was increased as the age of seedlings was increased. However, there were significant differences among the treatments at $\mathrm{P}<0.05$ (Table 4) when the seeds were treated by dipping for 3
The minimum shoot length $(0.07$ and $0.13 \mathrm{~g})$ with plant height $0.20 \mathrm{~g}$ was observed in un-treated inoculated seeds followed by seeds dipped DNL decoction for 3 minutes $(0.07$ and $0.14 \mathrm{~g}$, shoot weight with $0.22 \mathrm{~g}$ plant weight), a decoction of NSWC for 3 minutes $(0.07$ and $0.16 \mathrm{~g}$ with plant height $0.25 \mathrm{~g}$ ), NSC for 3 minutes $(0.08$ and $0.18 \mathrm{~g}$, with $0.26 \mathrm{~g}$ plant weight), seeds dipped in DNL for 5 minutes $(0.09$ and $0.18 \mathrm{~g}$, having plant weight $0.26 \mathrm{~g}$ ) NSWC for 5 minutes $(0.09 \mathrm{~g}$ root and $0.19 \mathrm{~g}$ shoot weight with $0.28 \mathrm{~g}$ plant weight) and a decoction of SD for 3 minutes (Table 3 ). 
Azadirachta indica (neem) extracts could be used as potential fungicides against many plant pathogenic fungi. However, Mohammad (2000) reported that treatment with all concentrations of neem-based commercial product and neem seeds solvent extract at various periods of dipping time were not toxic to the tomato seedlings, whereas, improvements of plant weight and height were correlated to the reduction of nematode infestations. Babu et al., 2000a,b assessed the effects of Azadirachta indica products (leaf, neem seed kernel, and neem cake) on Alternaria solani in field and pot experiments using tomato $\mathrm{cv}$. PKM-1, results showed that the incidence rate of disease decreased compared with the control group. Bowers and Locke (2000) treated the soil infected by Fusarium oxysporum f. sp. chrysanthemi with 90\% Azadirachtin neem oil and reported that it reduces the number of pathogens and increases the healthy plant community reveals that the extract played an important role in the biological management strategy of controlling Fusarium wilt diseases. Faruk et al. (2001) reported that the treatment of soil with Azadirachtin leaf powder 10 grams per pot, 5 $\mathrm{kg}$ of pit soil, and 0.5 tons / ha can significantly reduce disease and improve plant growth (shoot length and weight, root weight). Khan and Siddiqui (2001) reported that Azadirachta indica had the greatest effect on the growth and weight of tomato and was the most effective. In other studies, Khan and Rathi (2001) reported that neem cake was the best at $25 \mathrm{q} /$ ha and improved tomato plant growth and yield in comparison to the untreated control. Randhawa et al. (2001) also reported a significant increase in height and weight of tomato seedlings when used neem cake, fresh leaves of Melia compacta, Melia azadirachta [Azadirachta indica], and other amendments. Seedling height in neem cake treatments was increased by $43.2 \%$ and the increase in seedling height was also observed in Melia compacta $(8.63 \mathrm{~cm})$ and Melia azadirachta $(8.46 \mathrm{~cm})$ treatments but was non-significant. Agbenin et al. (2004) stated that the attractiveness of using chemicals is declining due to health effects. Moreover, in most developing countries in the world, the chemicals needed are often out of reach of farmers. Therefore, they also searched for an alternative mode of control of Fusarium wilt and root-knot, the important diseases of tomato. Field plots without treatment and Furadan treatment were used as control. Neem seed powder significantly reduced the severity of Fusarium Wilt and root-knot disease in the greenhouse and field. The results showed that Azadirachta indica seed powder might be used to control root-knot nematode and fusarium wilt syndrome. Abbasi et al. (2005) investigated the effects of neem cake on plantparasitic nematodes, Verticillium Wilt, and seedling damping-off caused by Rhizoctonia solani and Pythium aphanidermatum showed that neem cake had no direct toxicity to the damping-off. Still, neem cake might have produced a kind of bioactive substance, and the climate during incubation could inhibit the disease.

\section{CONCLUSION}

In the present study, it is concluded that the infected root pieces showed brownish discoloration. The fungus produced white cottony mycelial growth with a large quantity of single-celled micro-conidia and curved 3-5 septate macro-conidia. Therefore, the fungus was identified as Fusarium oxysporum f. sp. lycopersici. Whereas the effect of different neem products on seed germination, plant growth (shoot and root length and weight), and mortality due to damping-off of tomato seedlings varied from one to another product when the seeds were treated by dipping for 3 and 5 minutes and sown in artificially infested soil. All the treatments showed a highly significant difference from one another at $\mathrm{P}<0.05$ and that the tested neem products found to be the most effective against tomato seedlings damping off caused by Fusarium oxysporum f. sp. lycopersici and enhanced seed germination and plant growth.

\section{REFERENCES}

Abbasi, P. A., E. Riga, K. L. Conn and G. Lazarovits. 2005. Effect of neem cake soil amendment on reduction of damping-off severity and population densities of plant-parasitic nematodes and soilborne plant pathogens. Canadian Journal of Plant Pathology, 27: 38-45.

Agbenin, N. O., A. M. Emechebe and P. S. Marley. 2004. Evaluation of neem seed powder for Fusarium wilt and Meloidogyne control on tomato. Archives of Phytopathology and Plant Protection, 37: 319-326.

Alajrami, M. A. and S. S. Abu-Naser. 2020. Type of tomato classification using deep learning. International Journal of Academic Pedagogical Research, 3: 2125.

Ali, T. E. S., M. A. Nasir and A. S. Shakir. 1992. In vitro evaluation of certain neem products as mould inhibitors against post-harvest fruit rotting fungi of tomato. Pakistan Journal of Phytopathology, 4: 5861. 
Amrendra, K., K. K. Prasad and B. P. Jain. 1997. Effect of organic amendments and chemicals on growth and yield of tomato (Lycopersicon esculentum Mill.). Journal of Research, Birsa Agricultural University, 9: 49-52.

Babu, S., K. Seetharaman, R. Nandakumar and I. Johnson. 2000a. Fungitoxic properties of some plant extracts against Alternaria solani, the tomato leaf blight pathogen. Journal of Ecotoxicology \& Environmental Monitoring, 10: 157-159.

Babu, S., K. Seetharaman, R. Nandakumar and I. Johnson. 2000b. Effect of selected plant extracts/oils against tomato leaf blight. International Journal of Tropical Agriculture, 18: 153-157.

Barnett, H. L. and B. B. Hunter. 1972. Illustrated genera of imperfect fungi. Minneapolis, Burgess Publishing Company.

Bhonde, S. B., S. G. Deshpande and R. N. Sharma. 1999. In vitro evaluation on inhibitory nature of some Neem formulations against plant pathogenic fungi. Hindustan Antibiotics Bulletin, 41: 22-24.

Black, L. L., S. K. Green, G. L. Hartman and J. M. Poulos. 1991. Pepper diseases: a field guide. Asian Vegetable Research and Development Center. PP. 98.

Bowers, J. H. and J. C. Locke. 2000. Effect of botanical extracts on the population density of Fusarium oxysporum in soil and control of Fusarium wilt in the greenhouse. Plant Disease, 84: 300-305.

El-Shami, M. A., N. G. H. Awad and N. A. R. Abd-El-Nour. 1993. Effect of fungicides and herbicides interactions on tomato demping-off and plant growth. Egyptian Journal of Agricultural Research, 71: 641-658.

Ellis, M. B. 1971. Dematiaceous hyphomycetes. Commonwealth Mycological Institute Kew, Surrey, England, 1-608.

Faruk, M. I., M. A. Bari, M. S. Nahar, M. A. Rahman and M. M. Hossain. 2001. Management of root knot nematode (Meloidogyne) of tomato with two organic amendments and a nematicide. Bangladesh Journal of Plant Pathology, 17: 27-30.

Gunasekaran, C. R., A. Vinayagamurrhy and R. Sundaram. 1994. Management of root knot nematode and damping off disease in tomato nursery. South Indian Horticultural Association, 42: 346-347.

Jiskani, A. M., Y. Samo, M. A. Soomro, Z. H. Leghari, Z. G. N. Gishkori, S. H. Bhutto and A. Q. Majeedano. 2021. A destructive disease of lentil: Fusarium wilt of lentil. Plant Archives, 21: 2117-2127.

Jones, J. B., T. A. Zitter, T. M. Momol and S. A. Miller. 2015. Diseases of tomato (Solanum lycopersicum L.). APS Publications.

Khan, A. A. and M. A. Siddiqui. 2001. Evaluation of nematicidal properties of Azadirachta indica, Tagetes patula, Ficus racemosa and Nerium indicum against Meloidogyne incognita attacking tomato. Bionotes, 3: 82.

Khan, M. L. and N. Rathi. 2001. Effect of organic amendments and carbofuran on Meloidogyne incognita population and yield in tomato. Indian Journal of Nematology, 31: 83-84.

Khan, T. A. and S. K. Saxena. 1997. Integrated management of root knot nematode Meloidogyne javanica infecting tomato using organic materials and Paecilomyces lilacinus. Bioresource Technology, 61: 247-250.

Khokhar, K. M. 2013. Present status and prospects of tomatoes in Pakistan. Agricultural Corner-Farmers to Global Market, 1-21.

Kumaran, S. S., S. Natarajan and S. Thamburaj. 1998. Effect of organic and inorganic fertilizers on growth, yield and quality of tomato. South Indian Horticultural Association, 46: 203-205.

Kuprashvili, T. D. 1996. The use of phytoncides for seed treatment. Zashchita i Karantin Rasteniǔ, 5: 31.

Lucas, G. B. and L. Campbell. 2012. Introduction to plant diseases: identification and management. Springer Science \& Business Media.

Lukyanenko, A. N. 1991. Disease resistance in tomato. Springer, 99-119

Mohammad, A. 2000. Evaluation of the nematicidal effects of a neem-based product against root-knot nematode on tomato. International Pest Control, 42: 16-17.

Pandey, A. K., S. K. Sain and P. Singh. 2016. A Perspective on integrated disease management in agriculture. Bio Bulletin, 2: 13-29.

Randhawa, N., P. K. Sakhuja and I. Singh. 2001. Management of root knot nematode Meloidogyne incognita in tomato with organic amendments. Plant Disease Research Ludhiana, 16: 274-276.

Sajjad, M., M. Ashfaq, A. Suhail and S. Akhtar. 2011. Screening of tomato genotypes for resistance to tomato fruit borer (Helicoverpa armiger Hubner) in Pakistan. Pakistan Journal of Agricultural Sciences, 48: 59-62. 
Salman, M. and R. Abuamsha. 2012. Potential for integrated biological and chemical control of damping-off disease caused by Pythium ultimum in tomato. BioControl, 57: 711-718.

Schwinn, F. 1994. Seed treatment- A panacea for plant protection. British Crop Protection Council, Farnham, Surrey, UK.

Sharma, N. 1995. Effect of leaf powder/extract of Neem and Persian lilac on post-harvest diseases of tomato fruit. National Academy Science Letters, 18: 11-14.

Walia, K. K., N. Mehta and D. C. Gupt. 1994. Effect of Green manuring on Rhizoctonia and root-knot nematode complex on tomato. Nematologia Mediterranea, 22: 131-133.

Wong, M. Y. 2003. Fusarium oxysporum f. sp. lycopersici (Sacc.) WC Snyder and HN Hans. Spring.

Zulfikar, A., I. N. Layla, C. Preecha, W. Seephueak and P. Seephueak. 2018. Use of antagonistic bacteria from spent mushroom compost for controlling dampingoff caused by Fusarium solani in tomato. Asian Academic Society International Conference. PP. 630-638.

$\begin{array}{ll}\text { Contribution of Authors: } & \\ \text { Ali H. Mangi } & : \text { Performed the experiment and wrote the manuscript } \\ \text { Absar M. Jiskani } & : \text { Review the manuscript and contributed to the final version } \\ \text { Muhammad I. Khaskheli } & : \text { Supervised and designed the experiment } \\ \text { Muhammad M. Jiskani } & : \text { Supervised and designed the experiment } \\ \text { Gul B. Poussio } & : \text { Review manuscript } \\ \text { Rawal A. Qambrani } & : \text { Performed the experiment } \\ \text { Mansoor A. Mahar } & : \text { Performed the experiment } \\ \text { Abrar M. Jiskani } & : \text { Edit manuscript }\end{array}$

